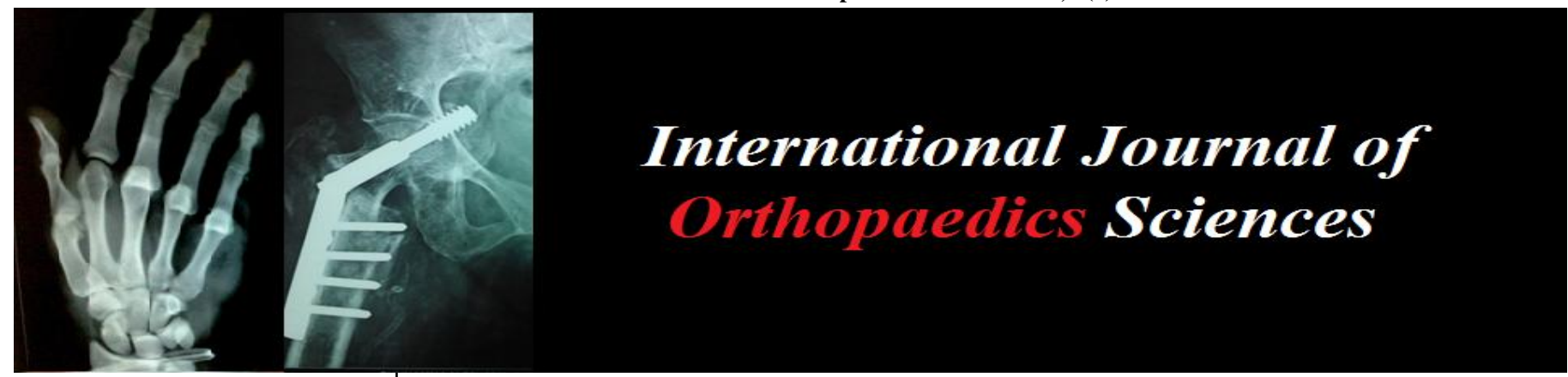

ISSN: $2395-1958$

IJOS 2018; 4(1): 806-809

(C) 2018 IJOS

www.orthopaper.com

Received: 07-11-2017

Accepted: 08-12-2017

Sonu Tyagi

Asst. Professor, Department of Anatomy, NCCH, Israna,

Panipat, Haryana, India

Ravi Kant Narayan Junior Resident, Department of Anatomy, PGIMS, Rohtak, Haryana, India
Correspondence

Ravi Kant Narayan

Junior Resident, Department of

Anatomy, PGIMS, Rohtak,

Haryana, India

\section{Study of the morphometric variations of the neural arch in the lumbar vertebrae in adult human skeleton of North Indian population}

\section{Sonu Tyagi and Ravi Kant Narayan}

DOI: $\underline{\text { https://doi.org/10.22271/ortho.2018.v4.i11.117 }}$

\section{Abstract}

Measurement of human vertebral geometry is important for accurate surgical procedures. The aim of this study is to measure the neural ach shape from $L_{1}$ to $L_{5}$. All Lumbar dry vertebrae $(N=150)$ of 30 individuals is measured and analyzed by gender. A Digital Vernier Caliper is used to measure the dimensions of the spinous (SP) and transverse (TP) processes, vertebral canal (VC), laminae, and isthmus. Most of the parameters are greater in males. Isthmus length decreases from $\mathrm{L}_{1}$ to $\mathrm{L}_{5}$ vertebrae in males with left side length greater than that of right in the lumbar region. In lumbar vertebrae transverse process length is increasing from $\mathrm{L}_{1}(17.83 \mathrm{~mm})$ to $\mathrm{L}_{3}(22.58 \mathrm{~mm})$ then decreasing till $\mathrm{L}_{5}(18.70 \mathrm{~mm})$ with right side length more than the left side at $\mathrm{L}_{1}$ to $\mathrm{L}_{5}$. Vertebral Superior Canal Width (VSCW) is increasing more than Vertebral Superior Canal length (VSCL) in lumbar vertebrae. The difference of width and length is increasing from $\mathrm{L}_{1}(5.65 \mathrm{~mm})$ to $\mathrm{L}_{5}(9.28 \mathrm{~mm})$. The shape of vertebral canal is oval in lumbar vertebrae. In conclusion, the neural arch is systematically asymmetrical and dynamic in shape along the lumbar spine.

Keywords: Neural Arch, Transverse Process, Spinous Process, Isthmus, Lamina, Lumbar

\section{Introduction}

Measurement of Neural Arch is important in surgical procedure. Spinous process height is the main factor for better surgical outcome. Transverse process and isthmus length dimensions are important in better acceptance of spinal graft during spinal surgery. Dimensions of neural arch are use in preparation of spinal fixation by translaminar screw.

A vertebra consists of two parts: vertebral body and neural arch. Neural arch is connected to the vertebral body by pedicles. Neural arch is made up of laminae and seven processes. These processes are right and left transverse process, spinous process, two superior articular facets and two inferior articular facets.

In human skeleton there are 5 lumbar vertebrae. Female has less kyphotic vertebral body then male. The vertebral body is wedge shaped in $\mathrm{L}_{1}$ and $\mathrm{L}_{2}$. It is not wedge shaped at $\mathrm{L}_{3}$ vertebrae. It is posteriorly wedged at $\mathrm{L}_{4}$ and $\mathrm{L}_{5}$ vertebrae. Vertebral body width increases from $\mathrm{L}_{4}$ to $\mathrm{L}_{5}{ }^{[3}$, 5].

Pedicles are most symmetrical in lumbar vertebrae ${ }^{[1,2]}$. Pedicles of $\mathrm{L}_{5}$ arise more literally from the body as compare to $\mathrm{L}_{3}$ vertebrae. ${ }^{3}$ Average pedicles width in female is $13 \mathrm{~mm}$ at $\mathrm{L}_{5}$. Pedicles width male is $12.8 \mathrm{~mm}$ at $\mathrm{L}_{5}{ }^{[4]}$.

Vertebral facets are oriented more vertically in thoracic and lumbar vertebrae and independent of age and gender. The dimensions of facet are more in male than female. In individual with spondylolysis is having significant greater inter-facet width and shorter inter-facet height. Lumbar facet joint continues to grow in boys after maturity as compare to the girls ${ }^{[4-9]}$.

Most of the morphometric studies had been mainly done on vertebral shape, pedicles dimensions and facet orientation. These parameters are essentially for making clinical diagnosis. But now-a-days spinal surgery is increasing day by day and requiring more spinal graft and spinal fixation. So, the neural arch parameters become more important. 


\section{Materials and methods}

The study is done on 30 human skeletons. 23 males and 7 female vertebrae are considered which were retrieved in the Department of Anatomy, PGIMS, Rohtak. All vertebrae and other bones are fully ossified, complete and non-pathological. The measurements include linear parameter and were taken with the help of Digital Vernier caliper. There are seven parameters:

Isthmus Length: Distance between most inferior point of superior articular facet and most superior point of inferior articular facet. Both Left Isthmus Length (LIL) and Right Isthmus Length (RIL) are measured. Holding the bone in lateral view. (Fig.1a, 1b)

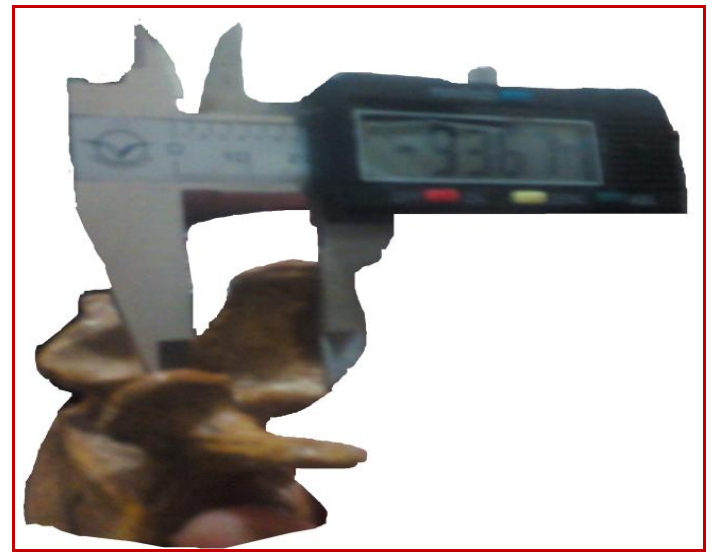

Fig 1a: Left Isthmus Length (LIL)

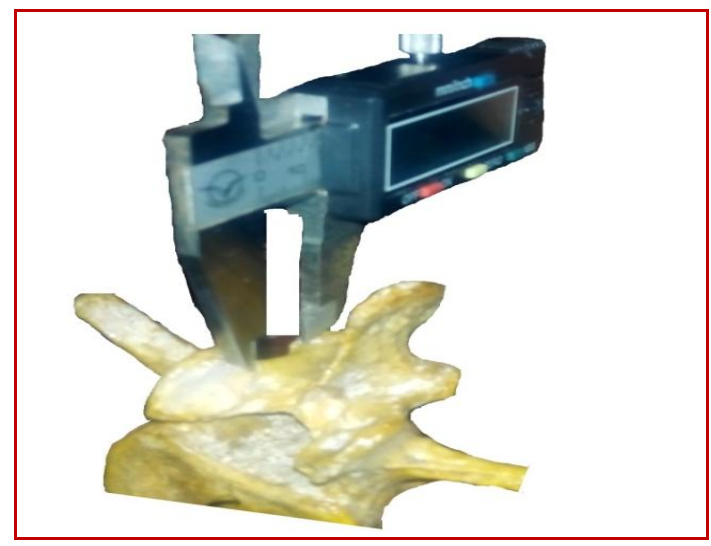

Fig 1b: Right Isthmus Length (RIL)

Spinous Process Length (SPL): Distance between most anterior and most posterior point on superior borders of spinous process in superior view. (Fig.2)

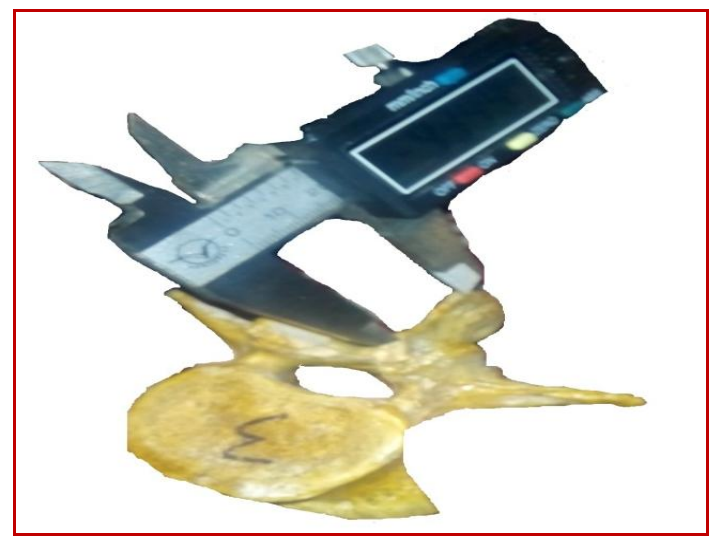

Fig 2: Spinous Process Length (SPL)
Spinous Process Height (SPH): Distance between posterior most point on superior border and posterior-most point on inferior borders of spinous process in lateral view. (Fig. 3)

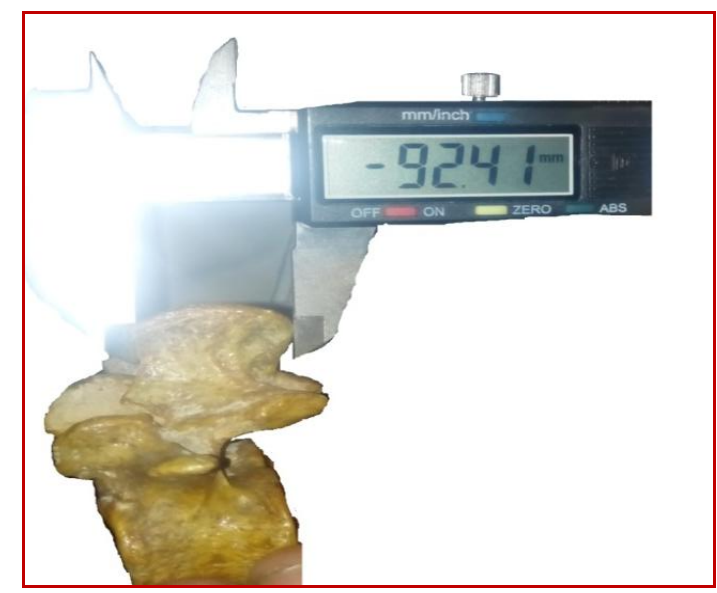

Fig 3: Spinous Process Height (SPH)

Transverse Process Length: Point A is highest point on external border of transverse process and the point $\mathrm{B}$ on lateral border of vertebral canal where superior artecular facets join the transverse process. The distance between point A and B is transverse process length. Both Left Transverse Process Length (LTPL) and Right Transverse Process Length (RTPL) are measured. (Fig. 4a, 4b)

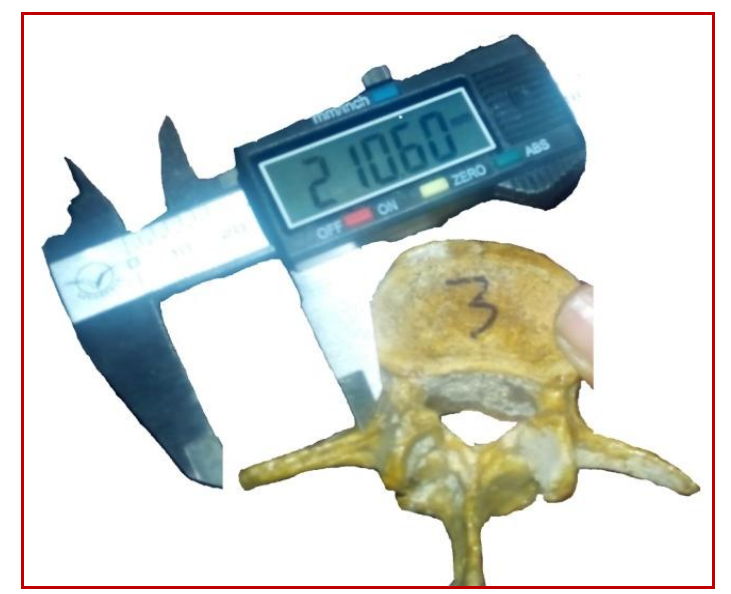

Fig 4a: Left Transverse Process Length

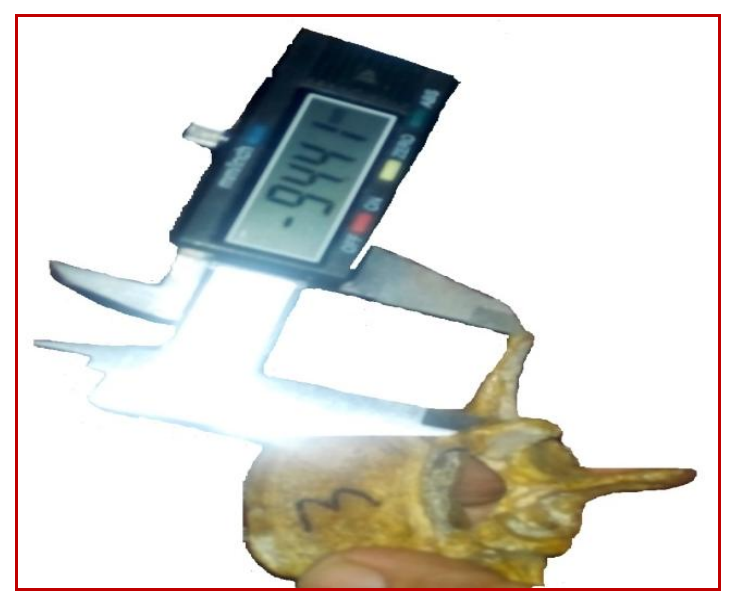

Fig 4b: Right Transverse Process Length

Vertebral canal superior width (VCSW): Maximum distance between left and right superior borders of vertebral canal. (Fig. 5) 


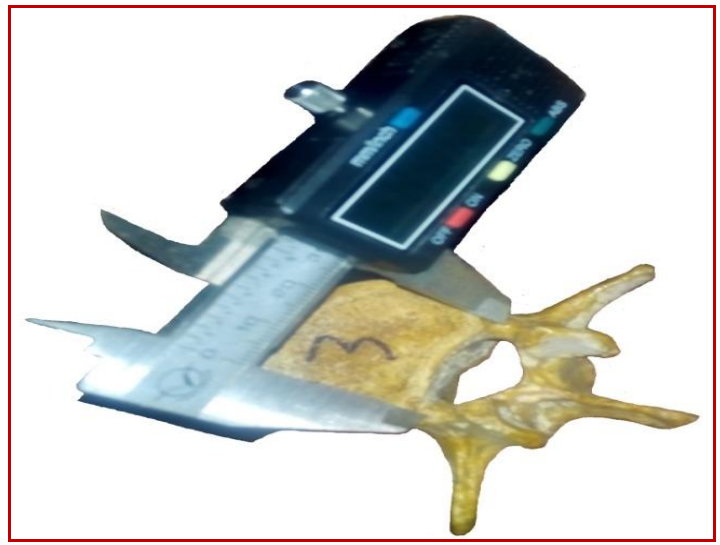

Fig 5: Vertebral canal superior width (VCSW)

Vertebral canal superior length (VCSL): Maximum distance between anterior most point on superior borders of spinous process and anterior most point on superior border of vertebral canal. (Fig. 6)

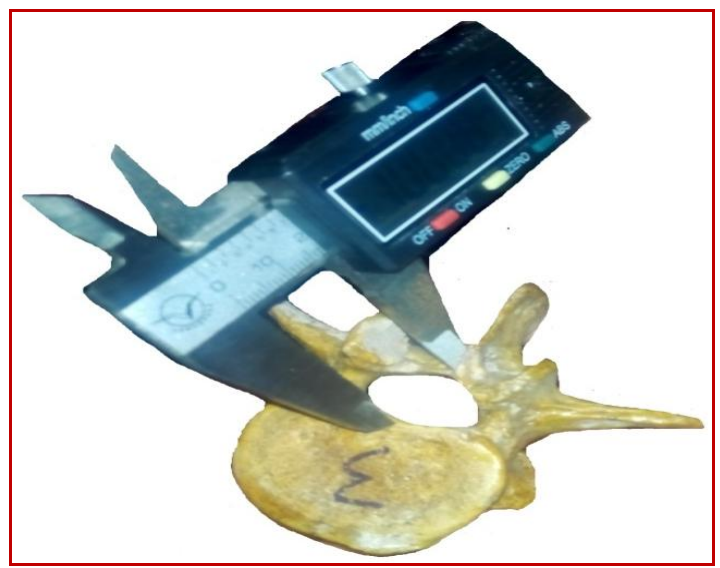

Fig 6: Vertebral canal superior Length (VCSL)

Laminar superior length: Distance between anterior most point on superior borders of spinous process and inferior most point on inferior border of superior facet. Both Left Laminar superior length (LSLL) and Right Laminar superior length (RSLL) are measured. (Fig. 7)

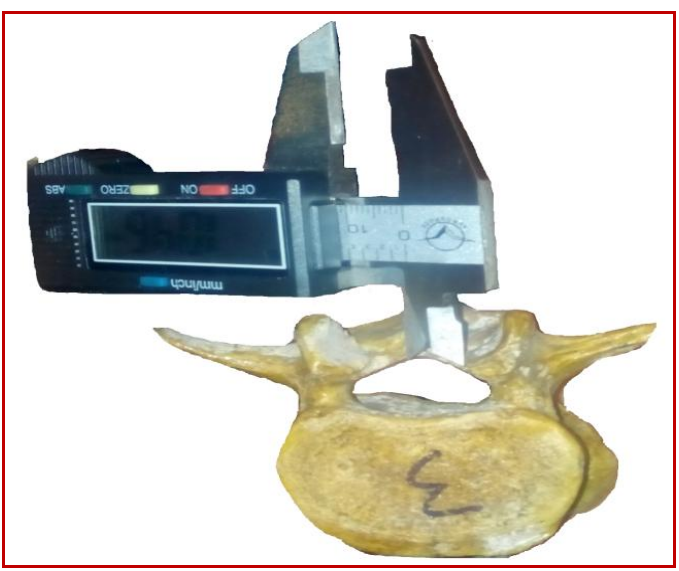

Fig 7: Laminar superior length

\section{Data Analysis}

Statistical analyses are performed using the Microsoft excel, version 2007. Descriptive Statistics are carried out for all measurements (mean and standard deviation). Paired t-tests are used to identify any vertebral asymmetry within the same individual. $\mathrm{P}$ value is calculated by Social Statistical Science version 17.0.

\section{Observation and Results}

Table 1: Isthmus Length measurements in Female Vertebrae

\begin{tabular}{|c|c|c|c|c|c|}
\hline & $\mathbf{L}_{1}$ & $\mathbf{L}_{2}$ & $\mathbf{L}_{3}$ & $\mathbf{L}_{4}$ & $\mathbf{L}$ 5 \\
\hline IL(R) & 17.06 & 16.84 & 16.8 & 13.37 & 9.53 \\
\hline S.D & 3.67 & 4.25 & 1.61 & 2.56 & 1.57 \\
\hline IL(L) & 17.44 & 17.52 & 14.27 & 14.37 & 10.99 \\
\hline S.D & 3.67 & 3.23 & 2.71 & 1.65 & 3.7 \\
\hline
\end{tabular}

Table 2: Spinous Process Length and Height measurements in Female Vertebrae

\begin{tabular}{|c|c|c|c|c|c|}
\hline & L1 & L2 & L3 & L4 & L5 \\
\cline { 1 - 3 } SPL & \multirow{2}{*}{$24.57+5.20$} & 25.94 & 29.28 & \multirow{2}{*}{$27.75+5.64$} & \multirow{2}{*}{$21.79+3.07$} \\
\cline { 1 - 3 } S.D & & 5.66 & 6.63 & & \\
\cline { 1 - 4 } SPH & \multirow{2}{*}{$18.24+3.85$} & 19.89 & 20.69 & \multirow{2}{*}{$20.63+1.95$} & \multirow{2}{*}{$14.72+1.81$} \\
\cline { 1 - 1 } S.D & & 3.19 & 3.49 & & \\
\cline { 1 - 3 } & & &
\end{tabular}

Table 3: Transverse Process Length measurements in female vertebrae

\begin{tabular}{|c|c|c|c|c|c|}
\hline & $\mathbf{L}_{\mathbf{1}}$ & $\mathbf{L}_{\mathbf{2}}$ & $\mathbf{L}_{\mathbf{3}}$ & $\mathbf{L}_{\mathbf{4}}$ & $\mathbf{L}_{\mathbf{5}}$ \\
\hline $\begin{array}{c}\text { TPL (R) } \\
\text { S.D }\end{array}$ & $15.24+5.37$ & 18.17 & 22.14 & \multirow{2}{*}{$19.26+1.80$} & $17.95+2.63$ \\
\cline { 3 - 5 } $\begin{array}{c}\text { TPL (L) } \\
\text { S.D }\end{array}$ & $11.98+3.20$ & 17.78 & 20.25 & \multirow{2}{*}{$18.26+3.11$} & $16.41+2.48$ \\
\cline { 3 - 4 } & & 2.47 & 2.79 & & \\
\hline
\end{tabular}

Table 4: Vertebral Superior Canal Width and Length measurements in female vertebrae.

\begin{tabular}{|c|c|c|c|c|c|}
\hline & $\mathbf{L}_{\mathbf{1}}$ & $\mathbf{L}_{\mathbf{2}}$ & $\mathbf{L}_{\mathbf{3}}$ & $\mathbf{L}_{4}$ & $\mathbf{L} \mathbf{5}$ \\
\hline $\begin{array}{c}\text { VSCW } \\
\text { S.D }\end{array}$ & $23.94+7.67$ & 23.67 & 24.88 & \multirow{2}{*}{$26.46+6.15$} & 29.87 \\
\cline { 1 - 3 } $\begin{array}{c}\text { VSCL } \\
\text { S.D }\end{array}$ & \multirow{2}{*}{$19.60+5.32$} & 7.2 & 6.62 & & 7.59 \\
\cline { 3 - 4 } & & 4.92 & 5.63 & $18.30+3.22$ & $18.09+1.32$ \\
\hline
\end{tabular}

Table 5: Laminar Superior Length measurements in female vertebrae

\begin{tabular}{|c|c|c|c|c|c|}
\hline & $\mathbf{L}_{1}$ & $\mathbf{L}_{2}$ & $\mathbf{L}_{3}$ & $\mathbf{L}_{4}$ & L5 \\
\hline \multirow{2}{*}{$\begin{array}{c}\text { LSL (R) } \\
\text { S.D }\end{array}$} & \multirow{2}{*}{$13.06+6.00$} & 14.11 & 13.48 & \multirow{2}{*}{$13.71+7.19$} & \multirow{2}{*}{$16.31+8.61$} \\
\hline & & 6.5 & 6.4 & & \\
\hline \multirow{2}{*}{$\begin{array}{c}\text { LSL (L) } \\
\text { S.D }\end{array}$} & \multirow{2}{*}{$12.64+2.69$} & 13.23 & 12.23 & \multirow{2}{*}{$12.04+3.98$} & \multirow{2}{*}{$14.55+3.90$} \\
\hline & & 3 & 2.62 & & \\
\hline
\end{tabular}

Table 6: Isthmus Length measurements in Male Vertebrae

\begin{tabular}{|c|c|c|c|c|c|}
\hline & $\mathbf{L}_{\mathbf{1}}$ & $\mathbf{L}_{\mathbf{2}}$ & $\mathbf{L}_{\mathbf{3}}$ & $\mathbf{L}_{\mathbf{4}}$ & $\mathbf{L}_{\mathbf{5}}$ \\
\hline IL(R) & 16.75 & 16.63 & 15.68 & 14.23 & 11.11 \\
\hline S.D & 3.79 & 2.79 & 2.89 & 2.77 & 2.26 \\
\hline IL(L) & 16.79 & 16.32 & 15.81 & 14.18 & 10.8 \\
\hline S.D & 2.82 & 2.64 & 2.51 & 2.83 & 2.26 \\
\hline
\end{tabular}

Table 7: Spinous Process Length and Height measurements in Male Vertebrae

\begin{tabular}{|c|c|c|c|c|c|}
\hline & $\mathbf{L}_{1}$ & $\mathbf{L}_{2}$ & $\mathbf{L}_{3}$ & $\mathbf{L}_{4}$ & L5 \\
\hline SPL & \multirow{2}{*}{$22.33+5.33$} & 24.71 & 27.16 & \multirow{2}{*}{$25.23+7.18$} & \multirow{2}{*}{$20.93+7.03$} \\
\hline S.D & & 5.86 & 5.95 & & \\
\hline SPH & \multirow{2}{*}{$20.21+5.21$} & 20.95 & 22 & \multirow{2}{*}{$21.69+3.84$} & \multirow{2}{*}{$16.69+2.71$} \\
\hline S.D & & 3.73 & 4.19 & & \\
\hline
\end{tabular}

Table 8: Transverse Process Length measurements in Male vertebrae

\begin{tabular}{|c|c|c|c|c|c|}
\hline & $\mathbf{L}_{1}$ & $\mathbf{L}_{2}$ & $\mathbf{L}_{3}$ & $\mathbf{L}_{4}$ & $\mathbf{L}_{5}$ \\
\hline \multirow{2}{*}{$\begin{array}{c}\text { TPL (R) } \\
\text { S.D } \\
\end{array}$} & \multirow{2}{*}{$17.81+6.54$} & 19.59 & 22.58 & \multirow{2}{*}{$20.94+3.78$} & \multirow{2}{*}{$18.70+5.47$} \\
\hline & & 3.96 & 4.39 & & \\
\hline TPL (L) & \multirow{2}{*}{$17.03+5.88$} & 19.08 & 22.01 & \multirow{2}{*}{$20.57+3.56$} & \multirow{2}{*}{$19.07+5.70$} \\
\hline S.D & & 3.88 & 3.99 & & \\
\hline
\end{tabular}


Table 9: Vertebral Superior Canal Width and Length measurements in Male vertebrae

\begin{tabular}{|c|c|c|c|c|c|}
\hline & $\mathbf{L}_{1}$ & $\mathbf{L}_{2}$ & $\mathbf{L}_{3}$ & $\mathrm{~L}_{4}$ & L5 \\
\hline \multirow{2}{*}{$\begin{array}{c}\text { VSCW } \\
\text { S.D }\end{array}$} & \multirow{2}{*}{$26.89+3.00$} & 26.55 & 27.83 & \multirow{2}{*}{$28.96+3.41$} & 30.55 \\
\hline & & 3.13 & 2.95 & & 3.19 \\
\hline VSCL & $2124+216$ & 20.72 & 20.18 & 20.42 & \\
\hline S.D & $21.24+2.10$ & 1.88 & 2 & 2.67 & $21.27+5.12$ \\
\hline
\end{tabular}

Table 10: Laminar Superior Length measurements in Male vertebrae.

\begin{tabular}{|c|c|c|c|c|c|}
\hline & $\mathbf{L}_{\mathbf{1}}$ & $\mathbf{L}_{\mathbf{2}}$ & $\mathbf{L}_{\mathbf{3}}$ & $\mathbf{L}_{\mathbf{4}}$ & $\mathbf{L}_{\mathbf{5}}$ \\
\hline \multirow{2}{*}{$\begin{array}{c}\text { LSL (R) } \\
\text { S.D }\end{array}$} & $11.32+2.21$ & 11.77 & 11.05 & \multirow{2}{*}{$11.15+1.96$} & $14.15+3.27$ \\
\cline { 3 - 5 } $\begin{array}{c}\text { LSL (L) } \\
\text { S.D }\end{array}$ & $11.19+2.26$ & 11.93 & 11.41 & \multirow{2}{*}{$11.59+1.96$} & $14.25+3.59$ \\
\cline { 3 - 4 } & & 2.02 & 1.68 & & \\
\hline
\end{tabular}

\section{Discussion}

Result shows that isthmus Length (IL) in Table 1 and 6, is decreasing from $L_{1}$ to $L_{5}$. Right isthmus length is lesser than left isthmus length in lumbar vertebrae. The gender variations in isthmus length shows higher reading in males than females. Spinous Process Length (SPL) in Table 2 and 7, is increasing in upper lumbar vertebrae and decreasing in the lower lumbar vertebrae. The length of spinous process in female vertebrae is more than male vertebrae.

Spinous Process Height (SPH) in Table 2 and 7, is increasing from $L_{1}$ to $L_{3}$ and decreasing from $L_{4}$ to $L_{5}$. Male vertebrae have greater spinous process height than female vertebrae.

Transverse Process Length (TPL) in Table 3 and 8, is from $L_{1}$ to $\mathrm{L}_{3}$ then decreasing till $\mathrm{L}_{5}$. Right transverse process length is more than left transverse process length. Male vertebrae are having greater transverse process length than female vertebrae.

Vertebral Superior Canal Width (VSCW) in Table 4 and 9 is more than Vertebral Superior Canal Length (VSCW) in lumbar vertebrae. The difference of width and length increases from $\mathrm{L}_{1}$ to $\mathrm{L}_{5}$. So, the shape of vertebral canal is oval in lumbar vertebrae.

Laminar Length (LSL) (Table 5 and 10) of Lumbar vertebrae is increasing from $\mathrm{L}_{1}$ to $\mathrm{L}_{5}$. Right laminar length is more than left laminar length in both male and female. Female vertebrae have more laminar length than male vertebrae. Gender variations are significantly seen in isthmus length. Other parameters are statically insignificant as p value $>0.05$.

The gender variations are found statistically non-significant in vertebral canal width, isthmus length and spinous process height. Parameters show greater value in male vertebrae than female vertebrae. This may be due to the fact that males have stronger musculature to maintain the stability of vertebral column as they do more physical work than females. This explanation is reinforced by the data that female possess relatively thinner spinous processes than male, thus providing greater lumbar interspinous space for a greater range of lumbar extension and greater lumbar lordosis.

As the right laminar length is longer than the left laminar length, so, the meeting point of two laminae shift to the left of median plane. Due to this shift, spinous process is not considered as a midpoint of neural arch. This is also suggested by Van Schaik in 1989 that spinous process position in an A-P radiograph, is an unreliable diagnostic guide in the lumbar spine.

Masharawi et al. in his study reported that the left transverse process length was more than right transverse process length. But in our present study it is found that the right transverse process length is more than the left transverse process length.
This contrast may be due to the adoption of different method of measurements and skeletons of different populations.

\section{Conclusion}

The neural arch is systematically asymmetrical and very dynamic in shape along the thoracic and lumbar spine. The size of most its parts are independent of gender. The transverse processes length, isthmus length and laminar length are more on the right side of vertebrae. Because of this asymmetry the spinous process cannot be used for midpoint measurements.

\section{References}

1. Masharawi Y, Salame K. Shape variation of the Neural Arch in the Thoracic and Lumbar Spine: Characterization and Relationship with the Vertebral Body Shape, Clinical Anatomy, 2011; 24:858-867.

2. Abbas J, Hamoud K, Masharawi Y, May H, Hay O, Medlej B et al. Ligamentumflavum thickness in normal and stenotic lumbar spines. Spine, 2010; 20:1225-1230.

3. Masharawi Y, Dar G, Peleg S, Steinberg N, Medlej B, May $\mathrm{H}$ et al. A morphological adaptation of the thoracic and lumbar vertebrae to lumbar hyperlordosis in young and adult females. Eur Spine J. 2010; 19:768-773.

4. Masharawi YM, Kjaer P, Bendix T, Manniche C, May H, Mirovsky Y et al. Lumbar facet and interfacet shape variation during growth in children from the general population: A three-year follow-up MRI study. Spine, 2009; 34:408-412.

5. Masharawi Y, Salame K, Mirovsky Y, Peleg S, Dar G, Steinberg $\mathrm{N}$ et al. Vertebral body shape variation in the thoracic and lumbar spine: Characterization of its asymmetry and wedging. Clin Anat. 2008; 21:46-54.

6. Masharawi Y, Dar G, Peleg S, Steinberg N, AlperovitchNajenson D, Salame K et al. Lumbar facet anatomy changes in spondylolysis: a comparative skeletal study. Eur Spine J. 2007; 16:993-999.

7. Andrew Williams, Richards LM Newell, Patricia Collins. Back and Macroscopic Anatomy of Spinal Cord. Gray's Anatomy 39th Edition. Churchill Livingstone (London): Harcourt publisher, 2005; 746-749.

8. Masharawi Y, Rothschild B, Dar G, Peleg S, Robinson D, Been E, Hershkovitz I. Facet orientation in the thoracolumbar spine: Characterization and biomechanical interpretation. Spine 2005; 30: 281-292.

9. Masharawi Y, Rothschild B, Dar G, Peleg S, Robinson $\mathrm{D}$, Been E et al. Facet orientation in the thoracolumbar spine: Three dimensional anatomic and biochemical analysis Spine, 2004; 29:1755-1763. 